\title{
Bilateral sacrospinous fixation without hysterectomy: 18-month follow-up
}

\author{
Mehmet Baki Şentürk ${ }^{1}$, Hakan Güraslan ${ }^{1}$, Yusuf Çakmak ${ }^{2}$, Murat Ekin ${ }^{1}$ \\ 'Clinic of Obstetrics and Gynecology, Bakırköy Dr. Sadi Konuk Training and Research Hospital, Istanbul, Turkey \\ ${ }^{2}$ Department of Obstetrics and Gynecology, Batman State Hospital, Batman, Turkey
}

\section{Abstract}

Objective: The aim of this study was to evaluate the results of bilateral sacrospinous fixation (SSF), which was performed with surgical mesh interposition and bilateral vaginal repair.

Material and Methods: Twenty-two patients underwent SSF between 2010 and 2012, and the results were evaluated retrospectively. The results at preoperative and postoperative $6^{\text {th }}, 12^{\text {th }}$, and $18^{\text {th }}$ months of the pelvic organ prolapse quantification system (POP-Q) and the Pelvic Organ Prolapse/Urinary Incontinence Sexual Questionnaire-12 (PISQ-12) were compared using Friedman and Wilcoxon Signed Ranks tests. Values of $\mathrm{p}<0.05$ and $<0.01$ were considered statistically significant.

Results: According to the POP-Q, significant healing was observed on all vaginal vault points $(\mathrm{p}=0.001)$, and no prolapse was observed until the 18-month follow-up stage. There were also prominent patients who felt satisfactory with respect to their sexual life according to PISQ-12 $(\mathrm{p}=0.001)$.

Conclusion: This technique appears to provide an adequate clinical resolution, and it may be the primary surgical option for women with pelvic organ prolapse. (J Turk Ger Gynecol Assoc 2015; 16: 102-6)

Keywords: Pelvic organ prolapse, surgical mesh, vaginal vault

Received: 29 December, 2014

Accepted: 08 March, 2015

\section{Introduction}

Pelvic organ prolapse (POP) is a common condition in women; the incidence increases during the post-menopausal period $(1,2)$. In POP, the bladder, uterus, and bowel can bulge into the vagina (3). Although this is not a life-threatening condition, it causes urinary and anal incontinence, pelvic discomfort, and discomfort during sexual intercourse, which negatively affects the quality of life (3).

The spontaneous recovery of POP is not possible. Treatment includes surgical and nonsurgical options. Surgery is an effective treatment. Nonsurgical treatment options (including behavioral therapy with pelvic floor muscle training and pessaries) are preferred for poor surgical candidates $(4,5)$. The goal of surgery is to increase the quality of life, restore the anatomy and functional status, and prevent the development of recurrent prolapse. Physicians must consider potential complications, de novo symptoms that may arise after anatomy is restored, and ultimately choose a procedure that is most appropriate for an individual patient (6). Apical support is the most important point for successful surgery $(7,8)$. Abdominal sacrocolpopexy (ASC) and vaginal sacrospinous fixation (SSF) offer a long-term efficiency of $78 \%-100 \%$ and $73 \%-97 \%$, respectively, in providing apical support (9). The advantage of SSF is that it does not require laparotomy and general anesthesia, the procedure is cost-effective, and early discharge is possible $(10,11)$.
In the present study, bilateral SSF with surgical mesh (Prolen ${ }^{\circledR}$; Ethicon, Norderstedt, Germany) was applied to 22 patients with POP of stages 2-4, and the results were compared by retrospective examination of the outcomes at the preoperative stage and at 18 months postoperatively.

\section{Material and Methods}

A total of 22 women with POP of stages 2-4 underwent bilateral SSF with surgical mesh (Prolen ${ }^{\circledR}$; Ethicon, Norderstedt, Germany) interposition and concurrent bilateral vaginal repair, with transobturator tape (TOT) procedure if urinary incontinence was present, in Batman State Hospital department of Obstetrics and Gynecology between 02.2011 and 08.2012. There is no urodynamics unit in this clinic. Hence, we evaluated all the patients by using the stress test before and after reduction of the prolapsed part. The inclusion criteria were grade 2 or more symptomatic apical prolapse. Women with prolapse and indications of hysterectomy were excluded. Patients who cannot receive general or regional anesthesia were also excluded. All patients were informed about the surgical procedure and the consent form was signed. None of the patients underwent hysterectomy. In the preoperative period, all patients were examined according to the pelvic organ prolapse quantification system (POP-Q), and Pelvic Organ Prolapse/Urinary Incontinence Sexual Questionnaire-12 
(PISQ-12) forms were completed. In addition, all patients were evaluated with Pap smear, and transvaginal ultrasonography was performed to evaluate endometrial thickness in postmenopausal patients. The operation time and the intraoperative and postoperative complications were recorded. All patients were re-examined according to the POP-Q system, and PISQ-12 forms were completed at 6,12 , and 18 months postoperatively (12). Treatment failure was defined as the presence of more than stage 1 prolapse. All surgeries were conducted under spinal anesthesia by a single surgeon experienced in pelvic floor surgery. Foley catheter was removed $6 \mathrm{~h}$ after surgery. Postvoiding residual volume was evaluated by the Foley catheter, and PVR of less than $50 \mathrm{ml}$ is considered to constitute adequate bladder emptying (13). Postvoidal residual volume was evaluated only in patients with stress urinary incontinence. All patients were discharged from the hospital on postoperative day 2 . There was no necessary approval of the local ethic community because of the retrospective design of the study.

The procedure was initiated with saline infusion from the posterior vaginal wall towards the ischial spine under the mucosa. After the initial midline incision was made on the posterior vaginal wall, digital blunt dissection of the coccygeus muscle was performed to access the sacrospinous ligament. The adipose tissue overlying the coccygeus muscle was removed to completely expose the sacrospinous ligament. A polypropylene suture (Prolen ${ }^{\circledR}$; Ethicon, Norderstedt, Germany) (no:1) was bilaterally placed on the sacrospinous ligament. The tips of the $5 \times 1.5 \mathrm{~cm}$ polypropylene mesh (Prolen ${ }^{\circledR}$; Ethicon, Norderstedt, Germany) were suspended over this suture. The mid-point of the mesh was attached to the mid-section of the posterior surface of the cervix with three stitches using polypropylene no:1 sutures (Prolen ${ }^{\circledR}$; Ethicon, Norderstedt, Germany) (Figure 1). Then, saline was infused laterally under the anterior vaginal wall. After midline incision, the dissection was extended laterally and the fascia of the obturator internus muscle was identified. The endopelvic fascia underlying the bladder was exposed, and midline fascial defects were repaired primarily using polypropylene no:0 sutures (Prolen ${ }^{\circledR}$; Ethicon, Norderstedt, Germany). Four or five stitches were bilaterally placed on the obturator internus fascia using polypropylene no:1 sutures (Prolen ${ }^{\circledR}$; Ethicon, Norderstedt, Germany). The other tip of the suture was placed on the opposing intact endopelvic fascia. The posterior edge of the endopelvic fascia was sutured with two or three nonabsorbable sutures (Prolen ${ }^{\circledR}$; Ethicon, Norderstedt, Germany). Paravaginal support was completed after the placement of the sutures. Then, bilateral SSL sutures were placed while controlling the mesh tension with a finger placed in the rectum. The posterior vaginal wall was closed and the perineal body was elevated. All patients were administered vaginal estrogen therapy for 1 month postoperatively.

\section{Statistical analysis}

The statistical analyses were performed using the Number Cruncher Statistical System (NCSS) 2007 and the Power Analysis and Sample Size 2008 statistical software (PASS Inc., Utah, USA). The Friedman test was used to compare preoperative and postoperative POP-Q examination findings and PISQ-12 results, and the Wilcoxon Signed Ranks test was used in the analysis of PISQ-12 results in the postoperative period. The level of statistical significance was set at $\mathrm{p}<0.01$ and $\mathrm{p}<0.05$. The post-hoc

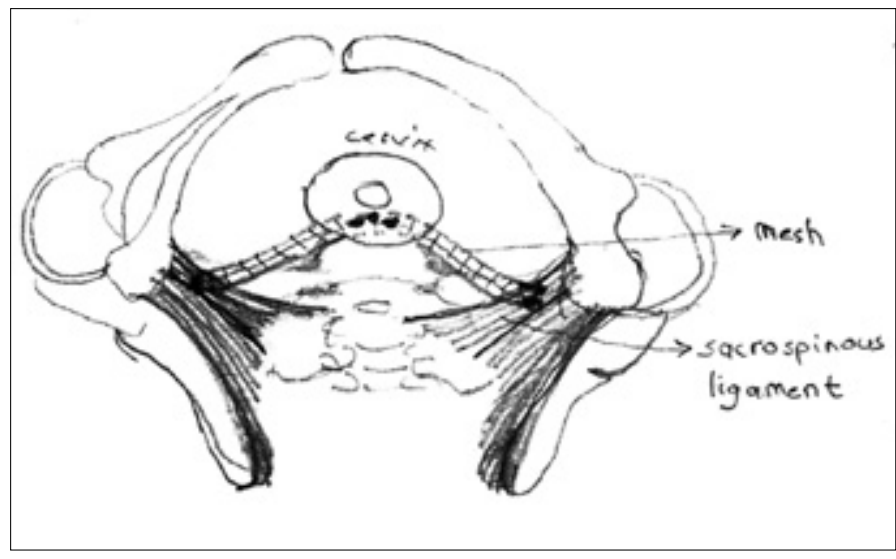

Figure 1. Surgery scheme

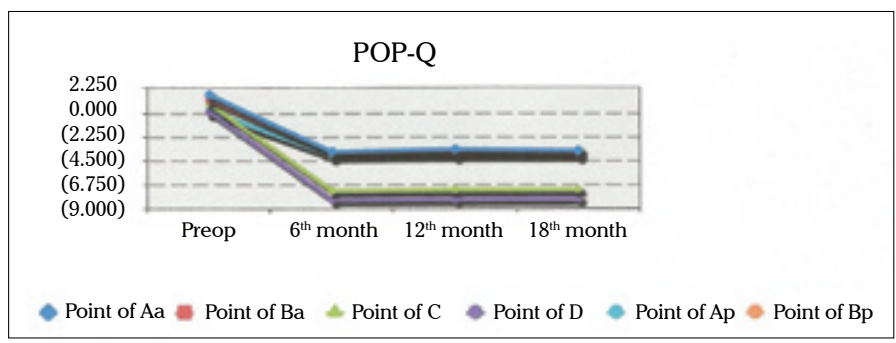

Figure 2. Changes in POP-Q examination

POP-Q: pelvic organ prolapse quantification system

Table 1. Classification of the patients according to disease status

\begin{tabular}{|l|l|c|c|}
\hline \multirow{2}{*}{ Complaint } & Palpable mass & n & \% \\
\cline { 2 - 4 } & Multiple complaints* & 10 & 45.5 \\
\hline Prolapse Stage & Stage 2 & 12 & 54.5 \\
\cline { 2 - 4 } & Stage 3 & 3 & 13.6 \\
\cline { 2 - 4 } & Stage 4 & 7 & 31.8 \\
\cline { 2 - 4 } SUI & No & 19 & 86.4 \\
\cline { 2 - 4 } & Yes & 3 & 13.6 \\
\cline { 2 - 4 } & Range & $38.6 \pm 13.9$ \\
\hline Age (years) & $24-70$ & \multicolumn{2}{|c|}{$5.6 \pm 2.27$} \\
\hline Parity & $2-9$ & Mean (SD) \\
\hline *Palpable mass+difficulty in defecation+painful sexual intercourse; discomfort \\
SUI: Stress urinary incontinence; SD: standard deviation \\
\hline
\end{tabular}

power analysis was performed with the study data using the G*Power (Version 3.1.7) program.

\section{Results}

The age of the patients was between 24 and 70 years with the mean of $38.8 \pm 13.9$ years. Complaints, stages of prolapse, and presence of stress urinary incontinence are presented in Table 1. All patients underwent bilateral SSF with surgical mesh (Prolen ${ }^{\circledR}$; Ethicon, Norderstedt, Germany) interposition and bilateral paravaginal support, and three of the patients (13.6\%) also 
Table 2. The comparison of the prolapsed points before the operation and at 6,12 , and 18 months postoperatively

\begin{tabular}{|c|c|c|c|c|c|}
\hline $\mathrm{n}=\mathbf{2 2}$ & $\begin{array}{c}\text { Preoperative } \\
\text { Mean } \pm \text { SD }\end{array}$ & $\begin{array}{c}6 \text { Months } \\
\text { Mean } \pm \text { SD }\end{array}$ & $\begin{array}{l}12 \text { Months } \\
\text { Mean } \pm S D\end{array}$ & $\begin{array}{l}18 \text { Months } \\
\text { Mean } \pm S D\end{array}$ & ${ }^{\mathrm{a}} \mathbf{p}$ \\
\hline Aa Point & $1.69 \pm 0.62$ & $-3.68 \pm 0.43$ & $-3.46 \pm 0.89$ & $-3.58 \pm 0.41$ & $0.001 *$ \\
\hline C Point & $0.85 \pm 3.03$ & $-7.35 \pm 0.41$ & $-7.27 \pm 0.38$ & $-7.26 \pm 0.36$ & $0.001 *$ \\
\hline D Point & $0.07 \pm 2.79$ & $-8.20 \pm 0.31$ & $-8.16 \pm 0.36$ & $-8.13 \pm 0.37$ & $0.001 *$ \\
\hline
\end{tabular}

Table 3. The evaluation of PISQ-12 pain level scores during sexual intercourse (Question 5 ) and avoiding sexual intercourse (Question 8)

\begin{tabular}{|l|l|c|c|c|}
\hline \multicolumn{2}{|c|}{} & $\begin{array}{c}\text { Median } \\
\text { (Min-Max) }\end{array}$ & Mean \pm SD & \multirow{2}{*}{${ }^{\text {a }}$} \\
\hline \multirow{2}{*}{$\begin{array}{l}\text { PISQ 12 } \\
\text { (Question 8) }\end{array}$} & Preoperative & $1(1-3)$ & $1.35 \pm 0.67$ & \multirow{2}{*}{$0.001^{*}$} \\
\cline { 2 - 4 } & 6 Months & $5(2-5)$ & $4.65 \pm 0.74$ & \\
\cline { 2 - 4 } & 12 Months & $5(4-5)$ & $4.95 \pm 0.22$ & \\
\cline { 2 - 4 } & 18 Months & $5(5-5)$ & $5.00 \pm 0.00$ & \\
\hline \multirow{2}{*}{$\begin{array}{l}\text { PISQ 12 } \\
\text { (Question 5) }\end{array}$} & Preoperative & $2(1-3)$ & $1.75 \pm 0.64$ & \multirow{2}{*}{$0.001 *$} \\
\cline { 2 - 4 } & 6 Months & $4(3-5)$ & $3.90 \pm 0.55$ & \\
\cline { 2 - 4 } & 12 Months & $4(2-5)$ & $4.10 \pm 0.72$ & \\
\cline { 2 - 4 } & 18 Months & $5(3-5)$ & $4.65 \pm 0.59$ & \\
\hline
\end{tabular}

aFriedman Test * $\mathrm{p}<0.01$

PISQ-12: Pelvic organ prolapse/urinary incontinence sexual questionnaire-12; SD: standard deviation

Table 4. The comparison of the cases with respect to PISQ12 scores in the preoperative period and at 6,12 , and 18 months postoperatively

\begin{tabular}{|l|l|c|c|c|c|}
\hline $\mathbf{n}=20$ & & Min-Max & Median & Mean \pm SD & p \\
\hline \multirow{3}{*}{ PISQ-12 } & Preoperative $^{\mathrm{ABC}}$ & $30 / 43$ & 40.5 & $39.50 \pm 3.41$ & \multirow{2}{*}{$0.001^{*}$} \\
\cline { 2 - 5 } & 6 Months $^{\text {Ade }}$ & $38 / 46$ & 43.0 & $43.10 \pm 1.94$ & \\
\cline { 2 - 5 } & 12 Months $^{\text {Bdf }}$ & $41 / 46$ & 43.0 & $43.55 \pm 1.57$ & \\
\cline { 2 - 5 } & 18 Months $^{\text {Cef }}$ & $41 / 46$ & 43.0 & $42.95 \pm 1.15$ & \\
\cline { 1 - 5 } & & & &
\end{tabular}

*Repeated Measures Test where $\mathrm{p}<0.01$, Wilcoxon Signed Rank tests were used for the paired comparisons, and capital letters were used where $\mathrm{p}<0.01$, $\mathrm{p}$ values were A: 0.001, B: 0.001, C: 0.001, d: 0.216, e: 0.748, f: 0.110

PISQ-12: Pelvic organ prolapse/urinary incontinence sexual questionnaire-12; SD: standard deviation

underwent the TOT procedure. The mean operation time was $43 \pm 10$ min (min-max: 32-67). There was no excessive bleeding or injury to the neighboring organs. Only one patient $(4.5 \%)$ did not pass a stool in the postoperative period. This patient was administered laxatives on the $2^{\text {nd }}$ day, which failed to provide any relief. Therefore, the patient underwent a repeat surgery on postoperative day 5 , during which the mesh was separated in half and two pieces were placed lateral to the midline. This relieved the rectal pressure while maintaining apical support.
The comparison of preoperative and postoperative POP-Q results at 6,12 , and 18 months revealed strong significant differences for points $\mathrm{Aa}, \mathrm{Ba}, \mathrm{C}, \mathrm{D}, \mathrm{Ap}$, and Bp ( $\mathrm{p}=0.001)$. According to the POP-Q system, the recovery of the apical point and vaginal wall is remarkable in the postoperative period (Table 2, Figure 2).

In comparison to preoperative values, the rate of painful sexual intercourse and avoiding sexual intercourse because of vaginal bulging were significantly lower at 6,12 , and 18 months postoperatively $(p=0.001)$ (Table 3$)$.

The evaluation of the total PISQ-12 scores revealed significant improvement in the symptoms of the patients compared to the preoperative scores $(\mathrm{p}=0.001)$. There was no significant difference between postoperative PISQ-12 scores at 6,12 , and 18 months ( $\mathrm{p}>0.05)$ (Table 4).

If forces are between $99.6 \%$ and $100 \%, \alpha=0.05$ level in the POP$\mathrm{Q}$ scale up the six points of the effect size of $0.80-4.90$; with the study group consisted of 22 patients.

\section{Discussion}

This present study demonstrated that vaginal bilateral SSF with mesh established adequate pelvic support for genital organ prolapse until 18 months. If SSF is performed bilaterally, vaginal axis may be more close to the original anatomic position. This can satisfactorily improve the patients' sexual life.

Unilateral SSF has been recommended for the treatment of vaginal vault defects. Unilateral SSF appears satisfactory, with a low recurrence rate, but is associated with the anatomical distortion of the vagina and the rectum that may alter both sexuality and bowel function $(11,14)$. Furthermore, some authors hypothesize that the higher POP recurrence and dyspareunia rates after unilateral SSF may be due to a posterior deviation of the vaginal axis and a tensioned repair with surgeons using permanent sutures during a unilateral SSF $(15,16)$. Because of these reasons, some authors recommend bilateral SSF, and a few studies including small number of patients have focused on anatomical and functional results after bilateral SSF (17-21). David Montefiore et al. (17) reported that bilateral SSF using non-absorbable sutures increased optimal anatomical results (94.3\% objective and 93\% subjective cure) and quality of life. In another study, bilateral SSF has been performed with a synthetic mesh in 10 women. Anatomical results of these 10 women were compared with nulliparous women using magnetic resonance imaging (MRI). A study showed that MRI measurements 
of the distance between the vaginal apex and bony pelvic landmarks and the ischial spines were similar to the measurements in nulliparous women with normal support (18). This study is important because their technique is similar to our technique. Unfortunately, we did not evaluate the anatomical results by MRI or other radiological methods; however, we believe that the results are similar. On the other hand, we evaluated patients using the POP-Q system and PISQ-12 form and observed significant improvement after surgery $(p=0.001)$.

We did not perform hysterectomy because we believed that preserving the uterus was a factor that influenced the success of the technique. The uterus itself passively causes prolapse. Although hysterectomy does not increase the success rate of the procedure, patients who do not undergo hysterectomy have reduced blood loss, shorter operation time, and a lower rate of complications (22). According to Petros (23), the uterus is vital to the maintenance of pelvic floor structure and functions, and hysterectomy could pave the way for prolapse by decreasing the blood supply of the uterosacral and cardinal ligaments. Furthermore, the presence of the cervix is important for the continuity of the cervical ring; however, we believe that setting the distal point on the cervix instead of the vaginal mucosa may increase the efficiency of SSF. More sutures can be placed through more durable tissue in the cervix. If sutures are placed in the mucosa, there are higher chances of ruptures, and it is not possible to place multiple sutures. Therefore, none of the patients in the present study underwent hysterectomy and none developed recurrence during their follow-up period of 18 months $(p=0.001)$.

The complications of SSF are rare. A review that evaluated 22 studies encompassing $1229 \mathrm{SSF}$ operations reported life-threatening bleeding from the sacral or pudendal vascular structures in only three patients (0.2\%) (11). However, dyspareunia can pose an important problem after vaginal surgery. The studies have reported a de novo dyspareunia rate of $3.2 \%$ after SSF (24). In a study by Hefni et al. (25), only two patients (1\%) had de novo dyspareunia because of vaginal stenosis that developed in relation to perineorrhaphy. Similarly, Holley et al. (26) attributed dyspareunia to vaginal stenosis. In the present study, fixation of the mesh to the cervix instead of the vaginal mucosa and leaving the vaginal mucosa in place may have reduced the likelihood of dyspareunia. Local estrogen also may have contributed to this result. Two patients did not have sexual intercourse at all in the preoperative and postoperative period. The other patients reported significant improvement in Question 5 of the PISQ-12 form at 6,12 , and 18 months postoperatively compared to preoperative scores $(p=0.001)$. Another complication with respect to mesh is exposure and erosion. Although there was no erosion or exposure in the present study, Halaska et al. (27) reported that these rates are $20.8 \%$ and $37.5 \%$, respectively. They treated these complications by surgical resection and local estrogen therapy. Halaska et al. (27) also used local estrogen for all the patients who underwent vaginal bilateral SSF with mesh. We have concern regarding our patients' comprehension regarding vaginal hygiene. Hence, we used local estrogen until 1 month to contribute to mucosal healing.

The rate of de novo cystocele ranges from $5.8 \%$ to $21.3 \%$ after construction of apical support (28). Cystocele reportedly develops because of a shift in intra-abdominal pressure from the reinforced posterior compartment to the anterior compartment
(29). Simultaneous reinforcement of the anterior compartment or total repair of the prolapse may reduce the development of de novo defects. Brubaker et al. (30) reported that Burch colposuspension performed simultaneously with ASC reduced the development of stress urinary incontinence (SUI). Similarly, Sivaslioglu et al. (31) added Burch colposuspension to ASC because of the same reasons. In the present study, all patients underwent bilateral paravaginal support and primary repair if a midline fascial defect was present, and none of the patients developed a defect during a follow-up period of 18 months.

The anal functions may be affected after SSF. The pudendal nerve may be injured, which negatively affects the functions of the anal sphincter. In one study, 14 out of 200 cases developed de novo anal incontinence (32). In a study conducted by Vierhout et al. (33), one patient with stage 2 prolapse who underwent mesh repair of the posterior wall developed functional obstruction; the mesh was loosened because the patient did not respond to laxatives. The author suggested that sclerosis developed by the mesh on the rectum blocked rectal movement. In the present study, the tension of the mesh was tested with rectal examination before placing the mesh sutures. Nonetheless, one patient who did not respond to laxatives developed functional obstruction. In this patient, the mesh was not totally removed but rather cut from the midline in half. The two edges of the mesh were placed more laterally to re-establish apical support. During the follow-up period, the patient did not experience a recurrence of constipation.

The anatomic restoration is profoundly important in pelvic reconstructive surgery. MRI studies showed that ASC produces a vaginal axis closer to the original anatomic position than SSF (34). One study compared the outcomes of SSF, ASC, and posterior intra-vaginal sling (PIVS) using MRI to evaluate the vaginal axis and reported that PIVS produced the best outcomes and SSF produced the worst outcomes (15). However, this study only evaluated sagittal images, and no data was obtained regarding the difference in lateral deviation between ASC and PIVS because of the absence of coronal images. However, one important study was conducted by Nicolau-Toulouse et al. (18) Their technique is same as our technique, except for the use of capio suture capture device. Bilateral sacrospinous fixation was conducted in 10 patients. After bilateral sacrospinous fixation, these 10 patients were compared with 11 nulliparous women by MRI in three-dimensional planes. The average distance between vaginal apex and ischial spine was similar in sagittal, coronal, and axial planes. The most important limitation of the present study was the lack of a control group comprising patients who underwent PIVS or ASC. Another limitation was less patients, which did not allow evaluation of the complications. Nevertheless, the study contained a sufficient number of cases to suggest the efficiency of the operation. The fact that all patients were operated on by the same surgeon is another strength of the present study.

The present study presents a modified technique in prolapse surgery. The SSF procedure can produce a vaginal axis that is closest to the original anatomic position if it is performed bilaterally with surgical mesh interposition. If the procedure is performed without hysterectomy, durable and multiple sutures can be placed on the distal point, which increases the efficiency of the operation. Considering the costs and complications of abdominal surgery, this method may be the primary surgical option for women with pelvic organ prolapse. 
Ethics Committee Approval: N/A

Informed Consent: Written informed consent was obtained from patients who participated in this study.

Peer-review: Externally peer-reviewed.

Author Contributions: Concept - M.B.S..; Design - M.B.S..; Supervision - M.E.; Resource - M.B.S., Y.Ç.; Materials - M.B.S., Y.Ç.; Data Collection \& /or Processing - Y.Ç.; M.B.S..; Analysis \& / or Interpretation - H.G.; Literature Search - M.B.Ş.; H.G.; Writing - M.B.S.; Critical Reviews - M.E.

Acknowledgements: We want to special thanks the nurses and workers of operating room in Batman State Hospital.

Conflict of Interest: No conflict of interest was declared by the authors.

Financial Disclosure: The authors declared that this study has received no financial support.

\section{References}

1. Swift S, Woodman P, O'Boyle A, Kahn M, Valley M, Bland D, et al. Pelvic Organ Support Study (POSST): the distribution, clinical definition, and epidemiologic condition of pelvic organ support defects. Am J Obstet Gynecol 2005; 192: 795-806. [CrossRef]

2. Nygaard I, Barber MD, Burgio KL, Kenton K, Meikle S, Schaffer J, et al. Prevalence of symptomatic pelvic floor disorders in US women. JAMA 2008; 300: 1311-6. [CrossRef]

3. Tseng LH, Chen I, Chang SD, Lee CL. Modern role of sacrospinous ligament fixation for pelvic organ prolapse surgery--a systemic review. Taiwan J Obstet Gynecol 2013; 52: 311-7. [CrossRef]

4. Ng CC, Han WH. Comparison of effectiveness of vaginal and abdominal routes in treating severe uterovaginal or vault prolapse. Singapore Med J 2004; 45: 475-81.

5. Tenfelde S, Tell D, Thomas TN, Kenton K. Quality of Life in Women Who Use Pessaries for Longer Than 12 Months. Female Pelvic Med Reconstr Surg 2014. [Epub ahead of print]

6. Klauschie JL, Cornella JL. Surgical treatment of vaginal vault prolapse: a historic summary and review of outcomes. Female Pelvic Med Reconstr Surg 2012; 18: 10-7. [CrossRef]

7. Shull BL. Pelvic organ prolapse: anterior, superior, and posterior vaginal segment defects. Am J Obstet Gynecol. 1999; 181: 6-11. [CrossRef]

8. Toozs-Hobson P, Boos K, Cardozo L. Management of vaginal vault prolapse. Br J Obstet Gynaecol 1998; 105: 13-7. [CrossRef]

9. Morgan DM, Rogers MA, Huebner M, Wei JT, Delancey JO. Heterogeneity in anatomic outcome of sacrospinous ligament fixation for prolapse: a systematic review. Obstet Gynecol 2007; 109: 1424-33. [CrossRef]

10. Holley RL, Varner RE, Gleason BP, Apffel LA, Scott S. Recurrent pelvic support defects after sacrospinous ligament fixation for vaginal vault prolapse. J Am Coll Surg 1995; 180: 444-8.

11. Sze EH, Karram MM. Transvaginal repair of vault prolapse: a review. Obstet Gynecol 1997; 89: 466-75. [CrossRef]

12. Cam C, Sakalli M, Ay P, Cam M, Karateke A. Validation of the short forms of the incontinence impact questionnaire (IIQ-7) and the urogenital distress inventory (UDI-6) in a Turkish population. Neurourology and Urodynamics 2007; 26: 129-133. [CrossRef]

13. Tseng LH, Liang CC, Chang YL, Lee SJ, Lloyd LK, Chen CK. Postvoid residual urine in women with stress incontinence. Neurourol Urodyn 2008; 27: 48-51. [CrossRef]

14. David-Montefiore E, Garbin O, Hummel M, Nisand I. Sacro-spinous ligament fixation peri operative complications in 195 cases: visual approach versus digital approach of the sacro-spinous ligament. Eur J Obstet Gynecol Reprod Biol 2004; 116: 71-8. [CrossRef]

15. Rane A, Lim YN, Whithey J, Muller R. Magnetic resonance imaging findings following three different vaginal vault prolapse repair procedures: a randomized repair study. Aust N Z J Obstet Gynaecol 2004; 44: 135-9. [CrossRef]

16. Sze EHM, Meranus N, Kohli JR, Miklos JR, Karram MM. Vaginal configuration on MRI after abdominal sacrocolpopexy and sacrospinous ligament suspension. Int Urogynecol J Pelvic Floor Dysfunct 2001; 12: 375-80. [CrossRef]

17. David-Montefiore E, Barranger E, Dubernard G, Nizard V, Antoine JM, Daraï E. Functional results and quality-of-life after bilateral sacrospinous ligament fixation for genital prolapse. Eur J Obstet Gynecol Reprod Biol 2007; 132: 209-13. [CrossRef]

18. Nicolau-Toulouse V, Tiwari P, Lee T, Cundiff GW, Geoffrion R. Does bilateral sacrospinous fixation with synthetic mesh recreate nulliparous pelvic anatomy? An MRI evaluation. Female Pelvic Med Reconstr Surg 2014; 20: 222-7. [CrossRef]

19. Febrbraro W, Beucher G, Von Theobald P, Hamel P, Barjot P, Heisert M, Levy G. Feasibility of blateral sacrospinous ligament suspension with a stapler. Prospective studies with the 34 first cases. J Gynecol Obstet Biol Reprod 1996; 26: 815-21.

20. Pohl JF, Frattarelli JL. Bilateral transvaginal sacrospinous colpopexy: preliminary experience. Am J Obstet Gynecol 1997; 177: 1356-61. [CrossRef]

21. Shetty SD, Kirkemo AK. Bilateral bone anchor vaginal vault suspension: an initial report of a new technique. Tech Urol 1997; 3: 1-5.

22. Hefni M, El-Toucky T. Uterine prolapse in young women. Best Pract Res Clin Obstet Gynaecol 2011; 25: 157-65. [CrossRef]

23. Petros P. Influence of hysterctomy on pelvic floor disfunction. Lancet 2000; 356: 1275. [CrossRef]

24. Aigmueller T, Riss P, Dungl A, Bauer H. Long-term follow-up after vaginal sacrospinous fixation: patient satisfaction, anatomical results and quality of life. Int Urogynecol J Pelvic Floor Dysfunct 2008; 19: 965-9. [CrossRef]

25. Hefni MA, El-Toukhy TA. Long-term outcome of vaginal sacrospinous colpopexy for marked uterovaginal and vault prolapse. Eur J Obstet Gynecol Reprod Biol 2006; 127: 257-63. [CrossRef]

26. Holley RL, Varner RE, Gleason BP, Apffel LA, Scott S. Sexual function after sacrospinous ligament fixation for vaginal vault prolapse. J Reprod Med 1996; 41: 355-8.

27. Halaska M, Maxova K, Sottner O, Svabik K, Mlcoch M, Kolarik D, et al. A multicenter, randomized, prospective, controlled study comparing sacrospinous fixation and transvaginal mesh in the treatment of posthysterectomy vaginal vault prolapse. Am J Obstet Gynecol 2012; 207: 301.e1-7. [CrossRef]

28. Petri E, Ashok K. Sacrospinous vaginal fixation--current status. Acta Obstet Gynecol Scand 2011; 90: 429-36. [CrossRef]

29. Cosma S, Preti M, Mitidieri M, Petruzzelli P, Possavino F, Menato G. Posterior intravaginal slingplasty: efficacy and complications in a continuous series of 118 cases. Int Urogynecol J 2011; 22: 611-9. [CrossRef]

30. Brubaker L, Nygaard I, Richter HE, Visco A, Weber AM, Cundiff GW, et al. Two-year outcomes after sacrocolpopexy with and without burch to prevent stress urinary incontinence. Obstet Gynecol 2008; 112: 49-55. [CrossRef]

31. Sivaslioglu AA, Ilhan TT, Aydogmus S, Uzun M, Dolen I. The comparison of the anatomical and symptomatic outcomes of sacrocolpopexy and posterior intravaginal slingoplasty. Int Urogynecol J 2011; 22: 1363-8. [CrossRef]

32. Lovatsis D, Drutz HP. Safety and efficacy of sacrospinous vault suspension. Int Urogynecol J Pelvic Floor Dysfunct 2002; 13: 308-13. [CrossRef]

33. Vierhout ME, Withagen MI, Fütterer JJ. Rectal obstruction after a vaginal posterior compartment polypropylene mesh fixed to the sacrospinous ligaments. Int Urogynecol J 2011; 22: 1035-7. [CrossRef]

34. Sze EH, Meranus J, Kohli N, Miklos JR, Karram MM. Vaginal configuration on MRI after abdominal sacrocolpopexy and sacrospinous ligament suspension. Int Urogynecol J Pelvic Floor Dysfunct 2001; 12: 375-9; discussion 379-80. [CrossRef] 